\title{
A IMPLEMENTAÇÃO DE UMA SEQUÊNCIA DIDÁTICA PARA O ENSINO DO ARTIGO DE OPINIÃO NO ENSINO MÉDIO E O DESENVOLVIMENTO DE CAPACIDADES DE LINGUAGEM
}

\author{
Marilúcia dos Santos Domingos Striquer ${ }^{1}$ \\ Cláudia Roberta Consolin ${ }^{2}$
}

\begin{abstract}
RESUMO
Este artigo tem como principal objetivo investigar quais as capacidades de linguagem desenvolvidas nos alunos do terceiro ano do ensino médio no decorrer do processo de implementação de uma sequência didática realizada pela equipe integrante do PIBID/UENP, subprojeto Letras/Português, campus Jacarezinho. A referida sequência didática contempla o ensino e aprendizagem do gênero textual artigo de opinião e as capacidades de linguagem dizem respeito à capacidade de ação, à discursiva e à linguístico-discursiva. $\mathrm{O}$ arcabouço teórico que norteou todo o processo de elaboração da sequência, de implementação e das análises realizadas sobre as primeiras produções textuais dos alunos atendidos pelo projeto se constituem dos preceitos de Bakhtin (2003) e Marcuschi (2005) a respeito de gêneros discursivos/textuais, de Dolz, Noverraz e Schneuwly (2004) sobre sequência didática. Os resultados demonstraram que a capacidade de linguagem que mais os alunos desenvolveram foi a capacidade de ação.
\end{abstract}

PALAVRAS-CHAVES

Sequência Didática. Artigo de opinião. Gêneros textuais.

\section{INTRODUÇÃO}

Ao compreendermos, pautados nas orientações dos Parâmetros Curriculares Nacionais (PCNs) (BRASIL, 1998), que "ao professor cabe planejar, implementar e dirigir as atividades didáticas, com objetivo de desencadear, apoiar e orientar o esforço de ação e reflexão do aluno, procurando garantir aprendizagem efetiva" (p. 22), a equipe do subprojeto Letras/Português, da Universidade Estadual do Norte do Paraná (UENP), campus Jacarezinho, vinculado ao Programa Institucional de Iniciação à Docência (PIBID), desenvolveu e implementou um projeto para o ensino do gênero textual artigo de opinião em salas de aula dos últimos anos do ensino médio de escolas de Jacarezinho/Pr.

Durante o ano de 2014, participamos de todas as etapas de elaboração e de implementação da sequência didática que objetivou ensinar aos alunos a produzirem artigos de opinião. Nesse sentido, esse texto tem a intenção de apresentar a sequência didática e o processo de implementação, sobretudo, tendo como foco principal analisar quais as capacidades de linguagem foram desenvolvidas nos alunos do terceiro ano do ensino médio atendidos pelo subprojeto.

\footnotetext{
${ }^{1}$ Doutora em Estudos da Linguagem (UEL, 2013) e Professora da Universidade do Norte do Paraná.

${ }^{2}$ Aluna do Curso de Licenciatura em Letras e Bolsista PIBID da Universidade Estadual do Norte do Paraná.
} 
A sequência didática em questão foi elaborada e implementada tendo como base teórico-metodológica o Interacionismo Sociodiscursivo (ISD), o qual visa eventos de letramentos: projetos que organizam "estratégias de ensinagem para que os estudantes tenham acesso a práticas letradas situadas, [e que] viabilizam o agir desses estudantes em atividades significativas de linguagem que ocorrem em diferentes esferas sociais" (BALTAR, 2008, p. $564)$.

\section{GÊNERO TEXTUAL}

A origem dos gêneros textuais está diretamente relacionada às primeiras formas de comunicação entre a espécie humana, as quais se concretizam por meio de enunciados, organizadores das infinitas práticas comunicativas. De acordo com Marcuschi (2005), os gêneros são altamente maleáveis e se desenvolvem de acordo com a necessidade de um povo e de sua cultura, a fim de melhorar as formas de comunicação. Assim, os gêneros textuais são criados e se desenvolvem na coletividade, representando o poder do discurso na elaboração da interação social.

A referida definição de Marcuschi (2005) tem origem nos estudos de Bakhtin (2003), para quem qualquer utilização da língua efetua-se em forma de enunciados, que são unidades concretas e reais da comunicação discursiva, pertencentes aos sujeitos discursivos de uma ou outra esfera da atividade humana. Como resultado da participação em esferas, os gêneros assumem formas orais e escritas, e é nesse sentido que, de acordo com Bakhtin (2003), os gêneros sofrem, histórica e constantemente, mudanças, pois com a evolução da sociedade, gêneros orais foram transformados em escritos, por exemplo. Conforme Marcuschi (2005), com o desenvolvimento das civilizações e a descoberta da forma alfabética, o homem avançou para a comunicação escrita, surgindo assim novos gêneros, os quais foram assumindo novas formas, como as cartas, bilhetes, as notas comerciais, etc. E, de acordo com o autor, com a chegada da evolução industrial, e a criação da máquina impressa, surgiram outros novos gêneros textuais, como os jornais que ganhavam adeptos no mundo inteiro. Mas tudo se transformou de uma forma muito mais rápida, com o auge da revolução tecnológica, fazendo surgir o universo digital com milhares de novos gêneros tanto da esfera oral como escrita.

Contudo, definir o que são os gêneros textuais não é tarefa fácil, conforme defende Marcuschi (2005), já que por meio de muitos estudos chegou-se à conclusão que não é possível conceitua-lo exclusivamente por sua forma estrutural e linguística. Devendo-se levar em consideração os seus aspectos sócio-comunicativos e suas condições de usos, pois os 
gêneros não se constituem como formas estáticas e enrijecidas, sofrem alterações a todo momento ou até mesmo desaparecem em certas formas para surgir em outras novas, de acordo com a necessidade e criação humana (MARCUSCHI, 2005).

Além ainda do aparecimento de novos gêneros de acordo com a evolução da sociedade e da transformação de alguns outros, é preciso considerar a afirmativa de Bakhtin (2003) sobre a transmutação dos gêneros e a assimilação de um gênero por outro, como foi o caso da substituição da carta pelo o email, que têm a mesma funcionalidade, que é transmitir uma mensagem a um indivíduo, e que no caso do e-mail que estabeleceu um novo suporte e outra velocidade na entrega da mensagem, esse deixou até mesmo de ser compreendido como um gênero para o entendimento de que é um suporte de vários gêneros: como fotos, cartas de solicitação, cartas de reclamação, etc.

Em meio a tantos estudos e descobertas sobre os novos gêneros, algumas questões ainda são complexas a respeito de algumas denominações, como, por exemplo, a distinção entre o que é tipo textual e o que são gêneros textuais. Marcuschi (2005) elucida bem essa diferenciação: os tipos textuais formam a estrutura de um determinado enunciado/gênero textual. É de natureza linguística, englobando assim aspectos lexicais, sintáticos, tempos verbal e relações lógicas. Mais especificamente os tipos textuais fazem parte das seguintes categorias: narração, argumentação, descrição, exposição e injunção.

Os gêneros textuais, na exposição de Marcuschi (2005), são concretizados em textos e podem ser definidos por suas funcionalidades, seu tema, estilo e construção composição, afirmativa proveniente das definições de gêneros por Bakhtin (2003). Ainda de acordo com Marcuschi os gêneros atingiram uma quantidade imensurável e surgem novos ou deixam de existir de acordo com a necessidade humana, fica impossível de contabilizá-los. Mas, ressalta o autor que os gêneros existem nas diversas esferas sociais, exemplos: na esfera familiar: bilhete, lista de compras, conta de água e de luz, diálogo de instrução (entre pais e filhos), dialogo amoroso, lista telefônica, etc.; na esfera jornalística: notícia, reportagem jornalística, editorial, artigo de opinião, etc.; na esfera religiosa: sermão, oração, etc; na esfera escolar: resumo, texto dissertativo-argumentativo, aula expositiva, resenha, etc; na esfera humorística: piada, charge, etc.

É por assim se constituírem os gêneros textuais que Schneuwly (2004) considera "que toda a aprendizagem ocorre não individualmente, mas nas interações sociais" (p. 23), e a partir disso Dolz, Noverraz e Schneuwly (2004) elaboram uma sugestão para o ensino dos gêneros em sala de aula, proposta denominada de Sequência Didática. 


\section{SEQUÊNCIA DIDÁTICA}

Segundo Dolz, Noverraz e Schneuwly (2004), uma sequência didática (SD) pode ser definida como "um conjunto de atividades escolares organizadas, de maneira sistemática em torno de um gênero textual oral ou escrito" (p. 95), e podem possibilitar aos alunos uma maior eficiência no momento da aprendizagem, pois criam uma situação de interação entre os conhecimentos que o docente deseja abordar e aqueles que os alunos já têm pré-estabelecidos, promovendo o desenvolvimento cognitivo dos alunos, resultando em melhor desempenho da escrita e da oralidade.

Conforme Schneuwly e Dolz (2004), "se a comunicação se realiza por intermédio dos textos, deve-se possibilitar aos estudantes a oportunidade de produzir e compreender textos de maneira adequada a cada situação de interação comunicativa" (p. 78), assim, a melhor alternativa para trabalhar o ensino de gêneros é envolver os alunos em situações concretas de uso da língua de modo que consigam, de forma criativa e consciente, escolher meios adequados aos fins que se desejam alcançar. Assim, para Schneuwly e Dolz (2004), trabalhar com a elaboração e implementação de SDs é renovar as práticas pedagógicas, contribuindo para o nascimento de um cidadão letrado nas suas diversas capacidades comunicativas e escritas.

Para uma organização sistemática, Dolz, Noverraz e Schneuwlu (2004) apresentam um esquema de trabalho com a SD, a saber: 1- Apresentação da situação; 2- Produção inicial; 3-Módulos; 4- Produção final.

Na primeira etapa, a da Apresentação da situação, cabe ao docente realizar uma explicação aprofundada sobre o gênero textual que será trabalhado. O professor, nesse momento, deve apresentar aos alunos quem será o destinatário da produção; Que forma assumirá a produção; Quem participará da produção; deve elaborar uma coletânea de exemplares do gênero, para ajudar no entendimento e na definição do gênero.

$\mathrm{Na}$ etapa da Produção inicial, o professor deve propor ao aluno que elabore uma produção do gênero que foi proposto na apresentação da situação. Por meio desta atividade, o professor poderá avaliar em que nível de conhecimento o aluno se encontra, e traçar metas a atingir. Após as produções estarem concluídas, cabe ao professor analisá-las de modo minucioso, a fim de entender quais foram as dificuldades apresentadas pelos alunos, e de que modo o conhecimento prévio deles contribuiu para a produção. Assim cabe ao docente repensar sobre a sequência que foi elaborada ou que pretende elaborar, organizá-la com textos e atividades que beneficiem o desempenho e aprendizagem do aluno. 
Módulos - essa etapa tem como objetivo sanar problemas de maneira isolada e específica que foram diagnosticadas na produção inicial, tanto na esfera gramatical como discursiva. Essa fase é elaborada por intermédio de módulos que por sua vez são compostos por uma grande diversidade de exercícios que abordam as dificuldades apresentadas na primeira produção.

A produção final é a última etapa, nela caberá ao aluno aplicar de forma unificada todas as estruturas, organizações e regras específicas que aprendeu no decorrer dos módulos. Esse ciclo tem como finalidade avaliar o rendimento do discente. $\mathrm{O}$ objetivo é elaborar o gênero textual de forma consciente relembrando os procedimentos e ensinamentos vistos no decorrer dos módulos. É importante levar o aluno a refletir sobre o que aprendeu; sobre o que é preciso ainda aprender e fazer. A produção final serve de instrumento para regular e controlar o comportamento do produtor do texto, que ocorre durante a revisão e a reescrita, o que permite avaliar os progressos realizados no domínio do trabalhado.

Um dos fatores de maior relevância na aplicação da sequência didática é desenvolver nos alunos as capacidades de linguagem, definidas por Dolz e Scheneuwly (2004) como: capacidades de ação, capacidades discursivas e capacidades linguístico - discursiva. Segundo Dolz e Schneuwly (2004, p. 52) essas capacidades "evocam as aptidões requeridas do aprendiz para a produção de um gênero numa situação de interação determinada".

A capacidade de ação envolve o conhecimento prévio do aluno, aquele adquirido no decorrer da sua formação tanto intelectual como pessoal. E é o que proporciona que este identifique as questões que permeiam a situação de produção do texto, tais como: quem é o emissor; o papel social; quem é o público que se deseja atingir; qual o ambiente de produção; em que suporte o texto é veiculado; qual o objetivo da interação; qual o valor social que a produção ocupa na esfera humana.

A capacidade discursiva é o olhar atento que o aluno desenvolve no momento de identificar os tipos discursivos e os tipos de sequências que podem ser utilizadas nas suas produções ou enunciados, que estejam presentes no seu cotidiano. Os tipos discursivos são: teórico, relato, interativo e narrativo e discurso interativo. Já os tipos de sequência são: argumentativas, narrativas, descritivas, dialogais e explicativas (BUCKTA E STRIQUER, 2015).

A capacidade linguístico-discursiva diz respeito às determinadas escolhas que são feitas na elaboração de um gênero (oral ou escrito) e dizem respeito às escolhas gramaticais, lexicais e sintáticas e a outros mecanismos como os de textualização (conexão, coesão 
nominal e verbal) dentre outros recursos de modalizações que são fundamentais na construção dos enunciados.

Apresentadas as configurações teóricas a respeito de gênero, de sequência didática e das capacidades de linguagem a serem desenvolvidos no ensino de um gênero por meio de uma sequência didática, expomos a seguir, de forma sintética, a sequência elaborada pelo PIBID Letras/Português, campus Jacarezinho, para o trabalho com o artigo de opinião.

\section{A SEQUÊnCia didÁtica para O ENSINo do ARTigo de OPINIÃo no ENSINO MÉDIO}

Para a elaboração e implementação da sequência didática, a equipe do subprojeto PIBID realizou estudos teóricos a respeito dos pressupostos teórico-metodológicos do Interacionismo Sociodiscursivo (ISD), porque o ISD considera que o processo de ensino e aprendizagem de uma língua deve ter como objetivo o aperfeiçoamento das capacidades de linguagem dos alunos, a fim de facilitar a interação desse indivíduo com os outros e também com os diversos veículos de comunicação que estão expostos no meio social. Assim, entendese que trabalhar com as diversas formas de gêneros seria a melhor forma de adequar o aluno a esses princípios intelectuais e culturais.

A seguir, apresentamos um breve relato do trabalho realizado com os alunos do $3^{\circ}$ ano do ensino médio do Colégio Estadual Luiz Setti, na cidade de jacarezinho PR, no segundo semestre de agosto de 2014, uma das turmas atendidas pelo PIBID.

$\mathrm{Na}$ primeira aula de implementação foram feitas as apresentações formais dos bolsistas e do subprojeto PIBID. Em seguida, cada aluno recebeu um material didático impresso, composto da sequência didática para o ensino e a aprendizagem do gênero textual artigo de opinião. Cada bolsista também tinha seu material, o livro do professor, formado por orientações teórico-metodológicas e com sugestões de respostas aos exercícios.

Após a entrega do material, o gênero textual artigo de opinião foi apresentado para os alunos e foi definido que ao final de todo o processo, cada aluno elaboraria o seu artigo, o qual seria publicado em um mural, divulgado na feira de ciências da escola.

Em síntese, o trabalho de implementação se configurou da seguinte forma:

Apresentação da situação: Exposição do gênero textual artigo de opinião definição, importância e função que este gênero ocupa na esfera social. Definição da finalidade, do veículo do artigo a ser publicado pelos alunos no final da SD. 
Análise das condições de produção: todos os elementos que formam as condições de produção foram tomados como objeto de ensino, a seguir, reproduzimos uma das atividades como forma de exemplificação:

\subsection{Análise das Condições de Produção}

1. A partir do texto "Nosso Macunaíma é um Workaholic" responda:

a) Quem é o autor físico do texto?

b) Qual é a posição social do autor para falar sobre o tema em questão?

c) Quem é o destinatário (pretendido) do texto?

d) Qual foi o momento de produção do texto?

e) O momento de produção do texto influencia o ponto de vista da autora sobre o tema? De que forma?

f) Em qual veículo circulou o texto?

e) Qual o objetivo do texto:

Análise da arquitetura interna do texto: reconhecimento das partes que compõem um artigo de opinião, como: plano geral, tipos de discurso e sequencialidade. Exemplo de algumas das atividades:

Agora responda sobre o texto "A natureza pede socorro":

1. Qual é a questão polêmica apresentada pela autora?

2. Em qual das três partes do texto a autora apresenta o ponto de vista?

3. Em qual parte do texto a autora apresenta os argumentos para defender seu ponto de vista?

\section{Para ampliar seus conhecimentos}

Existem diferentes modos de construir argumentos consistentes e bem fundamentados para que sejam convincentes. Conheça alguns deles:

Argumento de autoridade: Ajuda a sustentar sua posição, lançando mão da voz de um especialista, uma pessoa respeitável (líder, artista, político, especialista), uma instituição de pesquisa considerada autoridade no assunto.

Argumento de exemplificação: Relata um fato ocorrido com ele ou com alguém para dar um exemplo de como aquilo que ele defende é válido.

Argumento de provas: Comprova seus argumentos com informações incontestáveis: dados estatísticos, fatos históricos, acontecimentos notórios.

(GAGLIARDI, Eliana; AMARAL, Heloisa. Ponto de Vista. São Paulo: Cenpec: Fundação Itaú Social; Brasília, DF: MEC, 2008, p. 37).

4. Cite dois argumentos utilizados pela autora para defender o ponto de vista dela.

5. Ao citar uma matéria da revista Veja em seu artigo, que tipo de argumento a autora utilizou? 
Análise dos elementos que compõem o estilo do gênero: recursos linguísticodiscursivos. Exemplo de uma das atividades:

\begin{tabular}{|l|l|}
\hline Recursos linguísticos & Respostas \\
\hline a) presença de pronomes da $1^{\mathrm{a}}$ pessoa & \\
(singular ou plural) - marcação de que a & \\
autora participa (ou simula participar) do & \\
tema da mesma forma que o leitor. & \\
\hline b) presença de pronomes que indicam & \\
que o tema em questão é (ou simula ser) & \\
de vivência tanto do leitor como da & \\
autora do texto. de elementos que & \\
\hline c) presença de que os acontecimentos & \\
demonstram que pelo tema ocorrem no momento & \\
tratados pelo do texto - marcando & \\
da produção do e leitor. & \\
proximidade entre a autora e o lor
\end{tabular}

Primeira produção: Como os textos produzidos pelos alunos participariam da feira cultural do colégio, definimos que o tema para o artigo a ser produzidos pelos alunos seria a "Ditadura militar", visto que esse acontecimento histórico estava complementando 50 anos, assim, na feira, montaríamos uma sala temática sobre o assunto.

O primeiro passo, definido o tema, foi oferecer aos alunos uma coletânea de textos a fim de que pudéssemos debater o assunto, e, em consequência, os discentes pudessem construir seus pontos de vista tendo condições de argumentar sobre o tema ${ }^{3}$.

Módulos: os bolsistas PIBID corrigiram as primeiras produções, tendo como critério a verificação de alguns aspectos como: adequação do título, dos elementos que formam o contexto de produção, a linguagem, a estrutura do texto, as marcas linguísticas e formatação geral. Contudo, antes de apresentar aos alunos as correções feitas pelos bolsistas, os discentes receberam a seguinte instrução:

Um texto sempre se oferece à inserção de novas ideias ou substituição de alguns termos ou expressões. Carlos Drummond de Andrade dizia que "escrever é lutar com as palavras". Você estudou muita coisa sobre artigo de opinião, e agora chegou o momento de rever a sua primeira produção. A reescrita de um texto não deve ser motivo para constrangimentos, mas sim a oportunidade de melhorar. Os grandes escritores e também os articulistas reescrevem seus textos quantas vezes forem necessárias antes de publicá-los.

3 Os textos de apoio para essa atividade foram: "Ditadura militar e o golpe militar de 1964" extraído de: https://goo.gl/cyl8; "Ditadura civil-militar: afasta de mim essa sombra", do Jornal Brasil de Fato, de 10 de agosto de 2014, disponível em https://goo.gl/9fF7sJ; "50 anos da ditatura militar", revista Caros amigos, de 04 de abril de 2014, disponível em: https://goo.gl/9uxEnk. 
Vamos seguir a dica? Para você avaliar o que ficou bom em seu texto e o que você ainda pode melhorar, analise sua produção considerando cada item contido na tabela a seguir:

Tabela de avaliação de seu artigo de opinião:

\begin{tabular}{|c|c|c|}
\hline Critérios & Sim & Não \\
\hline $\begin{array}{l}\text { 1.Adequação do título: } \\
\text { O título desperta a curiosidade do leitor? }\end{array}$ & & \\
\hline $\begin{array}{l}\text { 2.Adequação ao contexto de produção de linguagem: } \\
\text { A questão discutida é controversa e de relevância social? } \\
\text { Considera que conseguiu atingir seu objetivo de tentar convencer seus } \\
\text { leitores? }\end{array}$ & & \\
\hline $\begin{array}{l}\text { 3.Estrutura do texto: } \\
\text { No } 1^{\circ} \text { parágrafo você expôs seu ponto de vista? } \\
\text { Nos parágrafos centrais você apresentou argumentos para defesa de seu } \\
\text { ponto de vista? } \\
\text { Você apresenta uma conclusão para seu texto? }\end{array}$ & & \\
\hline $\begin{array}{l}\text { 4.Argumentação: } \\
\text { A seleção de informações é relevante para defender seu ponto de vista? }\end{array}$ & & \\
\hline $\begin{array}{l}\text { 5. Marcas linguísticas: } \\
\text { O emprego das conjunções está adequado? } \\
\text { Você utilizou vozes de autoridade em seu texto? } \\
\text { Os verbos foram empregados de forma adequada em cada uma das partes } \\
\text { do texto? }\end{array}$ & & \\
\hline $\begin{array}{l}\text { 6.Formatação geral: } \\
\text { As normas gramaticais foram empregadas de forma adequada? } \\
\text { As margens estão bem definidas? } \\
\text { Os parágrafos estão bem organizados? }\end{array}$ & & \\
\hline
\end{tabular}

Ao verificar que você marcou "não" para algum item, é necessário que você busque resolver o problema, para isto, conte com a ajuda de seu professor.

Após a identificação dos problemas e inadequações nos textos, a equipe do subprojeto elaborou uma série de atividades para o trabalho com as questões mais deficitárias.

Produção final: Esta etapa propõe ao aluno elaborar uma reflexão sobre a primeira produção, possibilitando o exercício da reescrita, aperfeiçoando assim colocações de ideias que talvez tenham sido utilizadas de forma deficiente na produção inicial. No momento da reescrita, o aluno está provido de estratégias sobre a composição do artigo de opinião. Logo, o exercício de escrita é uma tarefa que exige do seu produtor dedicação.

Os alunos digitaram seus textos finais no laboratório de informática do colégio, uma vez que, como posto, os textos seriam expostos na feira cultural que aconteceu no mês de setembro de 2014. A sala temática, desenvolvida em parceria com o PIBID de história da UENP, foi formada por fotos, vídeos, e os artigos de opinião dos alunos. O evento foi aberto ao público. 


\section{ANÁLISE DAS CAPACIDADES}

Para analisar as capacidades de linguagem desenvolvidas nos alunos atendidos pelo subprojeto, selecionamos um dos artigos por eles produzidos. Relembrando que o referido artigo foi fruto da primeira sequência elaborada e implementada em sala pelo projeto (PIBID), sendo necessário salientar que os trabalhos realizados pelo subprojeto tiveram continuidade e com o passar dos anos se dedicou a tarefa de reelaborarão e de aperfeiçoamento tanto da sequência didática como da formação da equipe que realiza o trabalho pedagógico.

O exemplar a seguir transcrito foi escolhido de forma aleatória, sem qualquer pretensão de favoritismo a um texto considerado melhor ou pior, é apenas um representante dos demais textos produzidos pelos alunos. O tema proposto, como mencionado, foi os "50 anos da ditadura militar no Brasil". Essa é a primeira produção do texto que, antes de ser apresentado na Feira Cultural do Colégio, passou pelo processo de correção dos pibidianos e por revisão e reescrita pelos alunos. Assim, a decisão de analisarmos a primeira produção justifica-se diante do fato de que nesse primeiro texto não há interferências dos corretores.

Exemplar da primeira produção dos alunos:

\section{A ditadura e a modernidade}

Sabemos que a ditadura militar foi um dos momentos mais marcante, e tristes da história do povo Brasileiro. O País era governado de forma manipuladora, a fimde ter o total controle sobre as pessoas.

A ditadura foi o poder concentrado na mão dos militare, que controlavam e reprimiam as pessoas na hora de pensar e agir muitas pessoas sofriam várias torturas e perseguições por irem contra o governo militar, estes eram obrigados a seguir esse regime obedecendo suas regras! O tempo passou e com ele a ditadura também, porém o que restou disto foram as marcas causadas por esse período.

Cinquenta anos se passaram, ma se engana quem acredita que as manipulações acabaram, sofremos com isso através da TV, rádio e jornais, muitos vivem em uma grande alienação, vêem e escutam notícias que muitas vezes não nos trazem a verdade de que precisamos.

A quem se engana achando que a ditadura acabou muito pelo contrário ela se encontra moderna e atualizada dentro de sua casa, para ser mais exato na sua TV e rádio, uma maneira de sair dessa manipulação, é procurar se informar, buscar novas informações, e outros meios de comunicação sem ser TV ou rádio, e formar assim sua própria opinião, sobre criticar e seguir sua linha de pensamento.

Buscando compreender, por meio, da produção do aluno, se ele desenvolveu, ou não, a capacidade de ação, retomamos a definição de que essa capacidade está relacionada ao fato de levar o aluno a fazer uso de um gênero a partir de uma prática social, ou seja, o aluno deve 
saber, nesse caso, produzir o artigo de opinião de acordo com a esfera social e da finalidade comunicativa do gênero. Assim, ressaltando, o trabalho todo do PIBID se voltou para que o aluno aprimorasse seus conhecimentos a respeito da produção de um artigo de opinião, em que pudesse apresentar um ponto de vista particularizado a respeito de um assunto polêmico e articular argumentos para defender e explicar seu posicionamento. Destacando que o texto foi elaborado a fim de ser apresentado na feira cultural do colégio e nesse sentido, é possível entender que o aluno desenvolveu a capacidade de ação, seu texto se relaciona com o tema proposto: há uma exposição narrativa do que foi a ditatura militar:

O País era governado de forma manipuladora, a fim de ter o total controle sobre as pessoas.

A ditadura foi o poder concentrado na mão dos militare, que controlavam e reprimiam as pessoas na hora de pensar e agir muitas pessoas sofriam várias torturas e perseguições por irem contra o governo militar, estes eram obrigados a seguir esse regime obedecendo suas regras!

Evidentemente, o que destacamos na construção da referida exposição narrativa não é o fato dela ser obrigatória ou constante em um artigo de opinião, mas sim a demonstração, no texto, de que o aluno desenvolveu a capacidade de ação no sentido de ser um ano do ensino médio, isto é, um indivíduo de 16 ou 17 anos, em média, portanto, totalmente distante, em tempo real cronológico, do ocorrido no período ditatorial, e, por isso, podemos compreender que partiu do princípio que era preciso contextualizar o que foi a ditadura militar para seu leitor: outros alunos da escola que participariam ou visitariam a feira cultural, onde o texto seria exposto. Assim, o olhar para seu destinatário e para a situação comunicativa da qual participaria seu texto é outro indício do desenvolvimento da capacidade de ação.

Outro ponto é o fato de que, no texto, há uma exposição de um ponto de vista e a tentativa de articular argumentos (essa questão trataremos de forma mais detalhada no momento de analisar a capacidade discursiva), questões as quais também estão ligadas a capacidade de ação.

A respeito da capacidade discursiva, que se refere ao autor de um texto saber organizar o plano geral, os tipos de discursos e as sequências que formam um gênero em específico. Em um artigo de opinião a organização é formada, segundo Buckta e Striquer (2015), por um título, o texto propriamente dito e a assinatura do autor, "o que é obrigatório, pois aquele que escreve se responsabiliza pelo proferido" (p. 1344). O texto em análise é construído por esse plano geral, evidentemente, nesse artigo, eliminamos o nome do autor, buscando preservar a identidade do sujeito de pesquisa, mas o texto original, publicado em mural na feira cultural 
trazia o nome do autor/aluno. $\mathrm{O}$ artigo foi escrito em prosa, acompanhando as linhas de uma folha de papel tradicional, possui no total de quatro parágrafos, cada um contendo aproximadamente oito linhas cada. O primeiro parágrafo configura-se como a introdução com a exposição do ponto de vista do autor: "a ditadura militar foi um dos momentos mais marcante, e tristes da história do povo Brasileiro"; "O tempo passou e com ele a ditadura também, porém o que restou disto foram as marcas causadas por esse período”. Os outros dois parágrafos são de desenvolvimento e o último a conclusão, os trataremos em outro momento.

Sobre os tipos de discurso, no artigo de opinião a predominância é a do discurso interativo, os elementos que sinalizam a interação são, por exemplo, o emprego de prenomes pessoais e possessivos de primeira pessoa do discurso, do singular ou do plural, ou a impessoalidade, que faz uso da terceira pessoa no singular (BUCKTA, STRIQUER, 2015). Elementos presentes no texto do aluno: Emprego da primeira pessoa do discurso, a qual marca a interação entre o autor e o destinatário por meio do texto: "Sabemos que a ditadura..."; “...sofremos com isso através da TV...”; “... não nos trazem a verdade de que precisamos”.

Quanto às sequências, no artigo de opinião há o predomínio da sequência argumentativa, justamente pela proposta do texto de persuadir o interlocutor (BUCKTA, STRIQUER, 2015), a qual pode ser identificado no texto, embora o aluno tenha desenvolvimento suas argumentações de maneira bastante superficial, não conseguindo articular explicações aos fatos narrados, sendo repetitivo, há presente de argumentos. Exemplos:

o tempo passou e com ele a ditadura também, porém o que restou disto foram as marcas causadas por esse período.

Cinquenta anos se passaram, ma se engana quem acredita que as manipulações acabaram, sofremos com isso através da TV, rádio e jornais, muitos vivem em uma grande alienação, vêem e escutam notícias que muitas vezes não nos trazem a verdade de que precisamos.

A quem se engana achando que a ditadura acabou muito pelo contrário ela se encontra moderna e atualizada dentro de sua casa, para ser mais exato na sua TV e rádio, uma maneira de sair dessa manipulação.

O terceiro parágrafo é uma repetição do segundo; apenas o aspecto da manipulação que ocorreu no período de ditadura militar é abordado, ainda assim sem aprofundamento de ideias e explicativas; há a afirmativa de que a sociedade precisa conhecer a verdade, a qual não é apresentada pela mídia, mas não trabalhou o que seria a verdade e em que sentido a mídia manipula as pessoas.

Ainda destacamos que, em sua organização estrutural, o texto é formado por uma conclusão que é "procurar se informar, buscar novas informações, e outros meios de 
comunicação sem ser TV ou rádio, e formar assim sua própria opinião, sobre criticar e seguir sua linha de pensamento". Conclusão essa não adequada, que não cerca as poucas ideias e argumentos apresentados no texto.

Nesse sentido, a afirmativa é a de que, em sua primeira produção, o aluno demonstra que desenvolveu a capacidade discursiva, organiza o artigo de opinião dentro do plano geral, e da predominância do tipo de discurso que o constitui; estrutura o texto em título, assinatura do autor, introdução, desenvolvimento, conclusão, em uma padronização canônica do gênero. Contudo, não apresenta um ponto de vista com ideias consistentes ou que se afastem de um senso comum, o que ocorre também com a articulação de argumentos. Assim, fica aparente a necessidade de um trabalho de mediação, da equipe do PIBID, a fim do desenvolvimento das capacidades discursivas dos alunos.

E os resultados de nossas análises sobre a capacidade linguístico-discursiva que envolve a seleção de mecanismos de textualização e enunciativos, os quais, de acordo com Buckta e Striquer (2015), "promovem articulações hierárquicas, lógicas e temporais do texto" (p. 1345), demonstraram que: $\mathrm{O}$ aluno retomou questões analisadas a partir do uso de elementos coesivos como o pronome, dando progressão ao conteúdo temático de forma a evitar repetições, alguns exemplos:

"Eram obrigados a seguir esse regime obedecendo suas regras" - os pronomes retomam por anáfora o tema ditadura.

“... muitas pessoas sofriam várias torturas e perseguições por irem contra o governo militar, estes eram obrigados a seguir esse regime obedecendo suas regras!" - o pronome, apesar o emprego inadequado, porque está no lugar do esse, retoma por anáfora o tema as pessoas.

"Cinquenta anos se passaram, ma se engana quem acredita que as manipulações acabaram, sofremos com $\underline{\text { isso }}$ através da TV...” - o pronome de substituição.

Sobre a disposição dos tempos verbais, o texto emprega de forma adequada o pretérito, mais na parte introdutória do texto, pois, como posto, há uma exposição do fato histórico, como pode ser observado:

Sabemos que a ditadura militar foi um dos momentos mais marcante...[...] O País era governado de forma manipuladora...

A ditadura foi o poder concentrado na mão dos militare, [...] muitas pessoas sofriam várias torturas e perseguições por irem contra o governo militar, estes eram obrigados a seguir esse regime obedecendo suas regras!

Nos parágrafos de desenvolvimento, os verbos estão no presente, uma vez que as reflexões sobre o tema correm no tempo da construção do texto, exemplos: 
Cinquenta anos se passaram, ma se engana quem acredita que as manipulações acabaram, sofremos com isso através da TV, rádio e jornais, muitos vivem em uma grande alienação, vêem e escutam notícias que muitas vezes não nos trazem a verdade de que precisamos.

A quem se engana achando que a ditadura acabou muito pelo contrário ela se encontra moderna e atualizada dentro de sua casa, para ser mais exato na sua TV e rádio...

Outra questão são os conectivos, fundamentais para estabelecer a ligação entre um argumento e outro e o fechamento das ideias apresentados em um texto de opinião (BUCKTA, STRIQUER, 2015). No texto, devido à articulação de argumentos e da construção da conclusão ser bastante frágil, insipiente, como mencionado, as conjunções necessárias não se fazem presentes.

Importante ainda destacar que o texto apresenta muitos problemas de ordem ortográfica, de concordâncias e de sintaxe. Alguns exemplos: Inadequações ortográficas: "militare"; "ma"; vêem. Uso incorreto de maiúscula: "povo Brasileiro"; "o País". Portanto, o texto demonstrou problemas com o desenvolvimento da capacidade linguístico-discursiva do aluno, indicando a necessária intervenção dos mediadores.

\section{CONCLUSÃO}

Apresentada a sequência didática e o processo de sua implementação e os resultados nas análises sobre as capacidades de linguagem que foram desenvolvidas nos alunos do terceiro ano do ensino médio, atendidos pelo subprojeto Letras/Português-CJ, no ano de 2014, nossas constatações finais são as de que, apesar do desempenho do aluno ter se mostrado positivo em alguns aspectos, como, por exemplo, o desenvolvimento da capacidade de ação e de alguns aspectos da capacidade discursiva, o texto evidenciou que havia muito a se trabalhar no que se refere às capacidades discursivas e linguístico-discursivas dos alunos.

Nesse sentido, após um levantamento das ações pedagógicas, a equipe concluiu que os resultados nos textos dos alunos são consequência de problemas encontrados no momento do trabalho do PIBID em sala de aula. Por exemplo, alguns exercícios focados na capacidade discursiva e ainda outros sobre recursos linguísticos-discursivos não foram completamente abordados em sala devido ao curto tempo para a implementação do projeto no seu todo, isto é, as poucas aulas entre o início do projeto e a data marcada para a feira cultural na escola. Contudo, o projeto alcançou seu objetivo de auxiliar os alunos no aprimoramento da produção do gênero artigo de opinião, como pode ser constatado pela equipe durante o processo de comparação entre as produções iniciais com os textos publicados na feira cultural. 
IMPLEMENTATION OF A SEQUENCE TEACHING FOR ARTICLE TEACHING VIEW IN SECONDARY EDUCATION AND LANGUAGE SKILLS DEVELOPMENT

\begin{abstract}
This paper aims to investigate what the language skills developed in the third year of high school students during the process of implementing a didactic sequence performed by integral team PIBID / UENP, subproject Letters / Portuguese campus Jacarezinho. Such didactic sequence includes the teaching and learning of genre opinion article and language capabilities relate to the ability to act, the discursive and linguistic-discursive. The theoretical framework that guided the entire development of the sequencing process, implementation and analyzes on the first textual productions of the students served by the project are the precepts of Bakhtin (2003) and Marcuschi (2005) concerning discursive / textual genres of Dolz, Noverraz and Schneuwly (2004) on teaching sequence. The results showed that the language ability that over the subproject team was able to develop in students was the ability to action
\end{abstract}

\title{
KEYWORDS
}

Didactic Sequence. Opinion article.Textual genres.

\section{REFERÊNCIAS}

BAKHTIN, M. Estética da Criação Verbal. São Paulo; Martins Fonte, 2003

BALTAR, M. Letramento radiofônico na escola. Linguagem em (Dis)curso. Tubarão/RS, v. 8, n. 3, p. 563-580, set./dez. 2008.

BRASIL, Ministério da Educação. Secretaria de Educação Fundamental. Parâmetros Curriculares Nacionais: terceiro e quarto ciclos: Língua Portuguesa. Brasília: MEC/SEF, 1998.

BUCKTA, M.; STRIQUER, M. S. D. O artigo de opinião: materialização de novas práticas sociais de linguagem. In: REIS, S.; EGIDO, A. A. (orgs.). Livro eletrônico: linguagem, ação e transformação. Londrina : UEL, 2016, p. 1341-1354. Disponível em: http://www.uel.br/projetos/iccal/

DOLZ, J.; NOVERRAZ, M.; SCHNEUWLY, B. Sequências didáticas para o oral e a escrita: apresentação de um procedimento. In: SCHNEUWLY, B.; DOLZ, J. e colaboradores. Gêneros orais e escritos na escola. Tradução e organização Roxane Rojo e Glaís Sales Cordeiro. Campinas/SP: Mercado das Letras, 2004, p. 95-128

MARCUSCHI, Luiz Antônio. Gêneros textuais: definição e funcionalidade. In: DIONÍSIO, A.P.; MACHADO, A.R.; BEZERRA, M.A. Gêneros textuais \& ensino. 4. ed. Rio de Janeiro: Lucerna, 2005, p. 19-36.

SCHNEUWLY, Bernard. Gêneros e tipos de discurso: considerações psicológicas e ontogenéticas. In: SCHNEUWLY, B.; DOLZ, J. e colaboradores. Gêneros orais e escritos na escola. Tradução e organização Roxane Rojo e Glaís Sales Cordeiro. Campinas/SP: Mercado das Letras, 2004, p. 21-40.

SCHNEUWLY, B.; DOLZ, J. Os gêneros escolares: das práticas de linguagem aos objetos de ensino. In: SCHNEUWLY, B.; DOLZ, J. e colaboradores. Gêneros orais e escritos na escola. Tradução e organização Roxane Rojo e Glaís Sales Cordeiro. Campinas/SP: Mercado das Letras, 2004, p. 71-92.

Data de recebimento: 13/09/2016

Data de aceite: $28 / 11 / 2016$ 